\title{
Pivotal prognostic and diagnostic role of the long non-coding RNA colon cancer-associated transcript 1 expression in human cancer (Review)
}

\author{
NI WANG ${ }^{1 *}$, YANG YU ${ }^{1 *}$, BOMING XU ${ }^{2}$, MINGJIONG ZHANG ${ }^{1},{\text { QUANPENG } \text { LI }^{1} \text { and LIN MIAO }}^{1}$ \\ ${ }^{1}$ Medical Center for Digestive Diseases, Second Affiliated Hospital, Nanjing Medical University, Nanjing, \\ Jiangsu 210011; ${ }^{2}$ Department of Gastroenterology, The Quanzhou First Hospital Affiliated to Fujian Medical University, \\ Quanzhou, Fujian 362000, P.R. China
}

Received March 20, 2018; Accepted October 30, 2018

DOI: $10.3892 / \mathrm{mmr} .2018 .9721$

\begin{abstract}
Long non-coding RNAs (lncRNAs) have been classically defined as regulatory RNA members $>200$ nucleotides in length, without detectable open-reading frames to encode proteins.Previous studieshave demonstrated that lncRNAsserve critical roles in multiple cancer types. Colon cancer-associated transcript 1 (CCAT1), a novel cancer-associated lncRNA, is significantly overexpressed in a number of malignancies. Functionally, as an oncogenic lncRNA, CCAT1 is involved in proliferation, migration, cell cycle progression, apoptosis, chemoresistance and other biological processes of cancer cells through complex regulation mechanisms in the cytoplasm or nucleus. In clinical applications, CCAT1 is additionally positively associated with histological differentiation, tumour node metastasis stage, vascular invasion, overall survival and recurrence-free survival, which demonstrates its important role as a diagnostic and prognostic marker in cancer. The present review summarises the current research progress of the oncogenic potential and clinical uses of CCAT1 in various human cancer types.
\end{abstract}

\section{Contents}

1. Introduction

2. Structure characterisation of CCAT1

Correspondence to: Dr Lin Miao or Dr Quanpeng Li, Medical Center for Digestive Diseases, Second Affiliated Hospital, Nanjing Medical University, 121 Jiangjiayuan, Nanjing, Jiangsu 210011, P.R. China

E-mail: linmiao@njmu.edu.cn

E-mail: 15150543586@163.com

* Contributed equally

Key words: long non-coding RNA, colon cancer-associated transcript 1 , cancer, oncogene, diagnosis, prognosis
3. Functions and mechanisms of CCAT1

4. IncRNA CCAT1 in human cancer

5. Future directions

\section{Introduction}

The increase of cancer occurrence is a health burden on society worldwide (1-3). More and better prediction models, including biomarkers or more complex bioinformatics, are required to provide early diagnosis and effective therapy for cancer.

Over the past decade, accumulating evidence has identified that $>90 \%$ of the human genome is transcribed, whereas, $<2 \%$ may be subsequently translated, which indicates that the majority of the genome generates many thousands of non-coding RNA (ncRNA) transcriptions (4). Benefiting from the immense technical advances in high-throughput sequencing of transcripts (5), numerous functional ncRNAs have been verified to direct post-transcriptional gene expression or guide RNA modifications rather than encode proteins in human cancer $(5,6)$.

Long non-coding RNAs (lncRNAs), ncRNA members, have been classically characterized as regulatory RNA molecules $>200$ nucleotides, without detectable open-reading frames to encode proteins $(7,8)$. Based on the transcript length, lncRNAs may be further classified as long-intergenic non-coding RNA, very long intergenic non-coding RNA, macroRNA or promoter-associated long RNA (9). Aberrant expressions of carcinogenic or tumour-suppressive lncRNAs have been identified in a broad spectrum of cancer types. Homeobox (HOX) transcript antisense RNA (HOTAIR) (10) serves as a pro-oncogenic capability marker, whereas, $\mathrm{X}$ inactive specific transcript (11) serves as a tumour suppressor. In addition, lncRNAs are involved in various biological processes, including cell proliferation (12), migration (10), differentiation (13), immune response (14) and apoptosis (15). Furthermore, as modulators in epigenetic processes, IncRNAs may adjust gene expression in chromatin modification, transcription, and post-transcriptional processing (16). In the nucleus, IncRNAs may serve as an organisational framework involved in interactions between proteins and between 
protein or DNA $(10,17)$, enhancing gene transcription from the enhancer regions (enhancer RNA) (18) or their neighbouring loci (ncRNA-a) (19). In the cytoplasm, lncRNAs serve as a sponge to titrate proteins $(12,20)$ or microRNAs (miRNAs/miRs) (21). These characteristics suggest the important roles of IncRNA applications in the diagnostic, prognostic and therapeutic evaluation of cancer.

The IncRNA termed colon cancer-associated transcript-1 (CCAT1), additionally termed LOC100507056 or cancer-associated region long non-coding RNA-5, has received increased attention among cancer-associated lncRNAs $(22,23)$. Since its identification, a number of previous studies demonstrated that CCAT1 is significantly upregulated in a number of malignancies and serves a pivotal role in tumourigenesis; it is thus of great value for diagnostic screening and therapy in cancer (24-26).

In the present review, the currently available studies of the clinical importance and functional regulatory mechanisms of lncRNA CCAT1 in various human cancer types are discussed.

\section{Structure characterisation of CCAT1}

CCAT1 was originally identified by Nissan et al (22) as a highly specific biomarker upregulated in colon malignancy. The CCAT1 gene is mapped to chromosome 8q24.21, which is described as a 'hot spot' containing single-nucleotide polymorphisms strongly involved in numerous cancer types (Figs. 1 and 2) $(22,27,28)$. Furthermore, CCAT1 spans a region of 2,628 base pairs in length and has two isoforms: CCAT1-S and CCAT1-L. CCAT1-L overlaps with CCAT1; however, CCAT1-L is exclusively positioned in the nucleus, whereas, the short isoform-CCAT1-S is cytoplasmic $(23,29)$. Additionally, downregulated CCAT1-L results in the simultaneous disruption of CCAT1-S, suggesting that CCAT1-S may be developed from CCAT1-L and that there may be a positive association between them (23).

\section{Functions and mechanisms of CCAT1}

CCAT1 has been reported to be significantly upregulated in various cancer tissues, including colorectal cancer (CRC), lung cancer (LC), gastric cancer (GC) and hepatocellular carcinoma (HCC), and is closely involved in proliferation, cell cycle, apoptosis, migration, invasion, chemoresistance and epithelial-to-mesenchymal transition (EMT) in various tumour cells (Table I). In addition, CCAT1 is positively associated with tumourigenesis, tumour invasion depth, lymph node metastasis, higher tumour node metastasis (TNM) stage and poor survival (Table II). Mechanistically, CCAT1, activated by c-Myc, may regulate target gene expression by binding protein to epigenetically modulate the promoter histone methylation of target gene expression in the nucleus (Fig. 2A and B), or serving as competing endogenous RNA (ceRNA) to sponge microRNA (Fig. 2C) and through involvement in the extracellular signal-regulated kinase/mitogen-activated protein kinase (ERK/MAPK) signaling pathway (Fig. 2D) in the cytoplasm. Notably c-Myc activates CCAT1, which enhances c-Myc expression via let-7, indicating there may be a feedback loop between them $(30,31)$.

\section{IncRNA CCAT1 in human cancer}

CRC. CRC, the second-leading cause of mortality in the United States, is a principal global health issue $(1,32)$. With the revelation of novel molecular and epigenetic mechanisms, IncRNAs, including HOX transcript antisense RNA (33), colon cancer-associated transcript 2 (34), metastasis-associated lung adenocarcinoma transcript 1 (35), carcinoembryonic antigen (36) and LINC00152 (37), have become biological targets for diagnostic, therapeutic and prognostic applications in patients with CRC. However, they all have limitations in the early diagnosis of CRC (38). Therefore, it is vital to identify novel bio-targets associated with CRC tumourigenesis (39).

Through reverse transcription-quantitative polymerase chain reaction analysis, Nissan et al (22) first demonstrated that CCAT1 expression levels in the mucosa of colon adenocarcinoma were significantly higher compared with normal colon tissues. A recent genome-wide association analysis in CRC demonstrated the same result (40). In addition, in the later stages of the disease, CCAT1 is strongly expressed in early stages of tumourigenesis, including tumour-proximal colonic epithelium and adenomatous polyps, which was demonstrated by Alaiyan et al (41) across the colon adenocarcinoma sequence. Elevated CCAT1 expression levels are positively associated with advanced clinical stages, lymphatic metastasis, local invasive depth, vascular invasion, CA19-9, recurrence-free survival (RFS) and overall survival (OS) (30,42-44). Furthermore, CCAT1 expression levels are significantly increased in the peripheral blood of patients with CRC. In particular, at a mild phase, increased CCAT1 combined with increased plasma HOTAIR was able to more powerfully diagnose patients with CRC from a group of healthy controls $(22,45)$. In addition, CCAT1-specific peptide nucleic acid-based molecular beacons have been identified as a diagnostic marker to detect CRC in vitro, ex vivo and in situ (46). However, because of the relatively small number of specimens in this previous study, extensive and multi-centre randomized controlled trials are required.

In vitro, CCAT1 is overexpressed in CRC-derived cells compared with normal colon-derived fibroblasts. Decreased CCAT1 was able to repress proliferation, migration, invasion and EMT, and led to G0/G1 cell-cycle arrest in CRC cell lines $(30,42,43)$.

Previous studies suggested that c-Myc, which is a pivotal transcriptional regulator significantly amplified in various types of cancer, may directly combine with E-box elements in the CCAT1 promoter regions to activate CCAT1 transcription (Fig. 2A) (30,42). Additionally, CCAT1 may serve as an enhancer-templated RNA to predict bromodomain and extraterminal (BET)-mediated c-Myc regulation, and BET inhibition JQ1 sensitivity in CRC, which has been observed in specific previous studies with certain haematological malignancies $(47,48)$.

This data suggests that the oncogene CCAT1 may serve as a novel biomarker for the early diagnosis and prognosis of CRC. In particular, it may be ideal for those patients who are sensitive to BET inhibitor-JQ1 in the treatment of CRC.

Laryngeal squamous cell carcinoma (LSCC). LSCC is the second most common head and neck malignancy (resulting in 

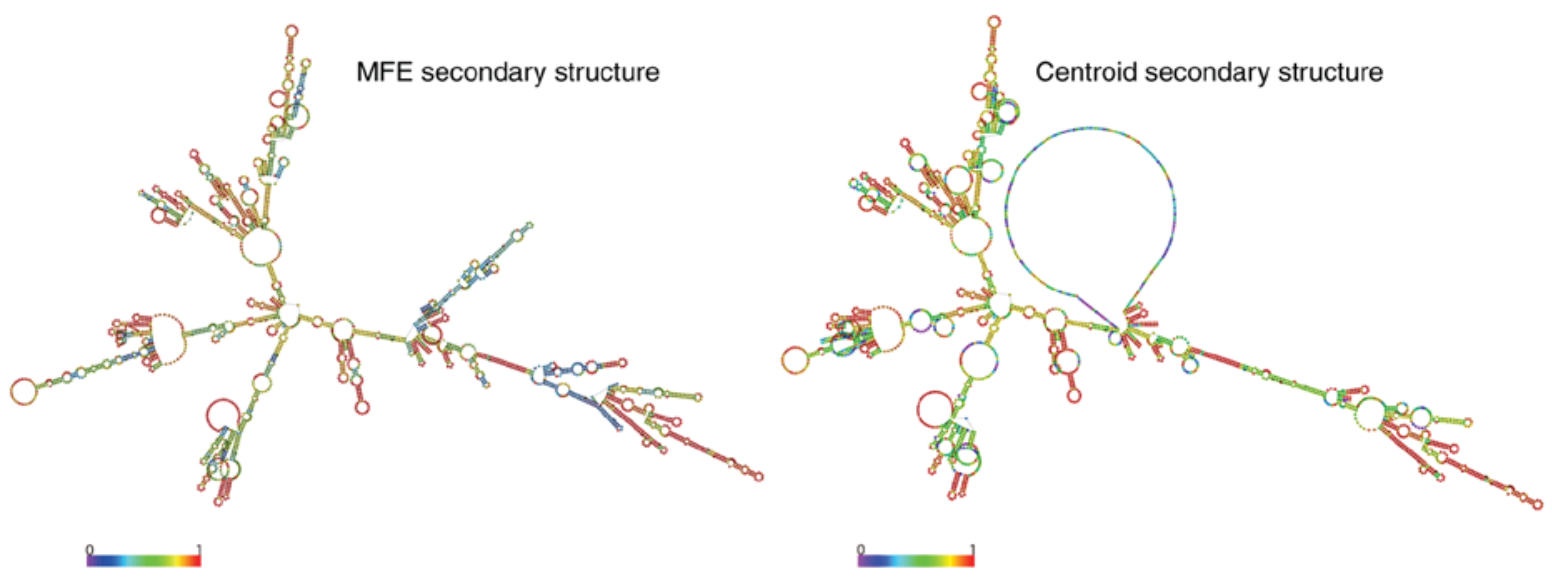

Figure 1. Coding potential analyses of CCAT1 transcripts. The CCAT1 prediction structure, according to MFE and partition function. The colour scale indicates the confidence of the prediction for each base, with shades of red indicating strong confidence (rna.tbi.univie.ac.at/). CCAT1, colon cancer-associated transcript 1; MFE, minimum free energy.

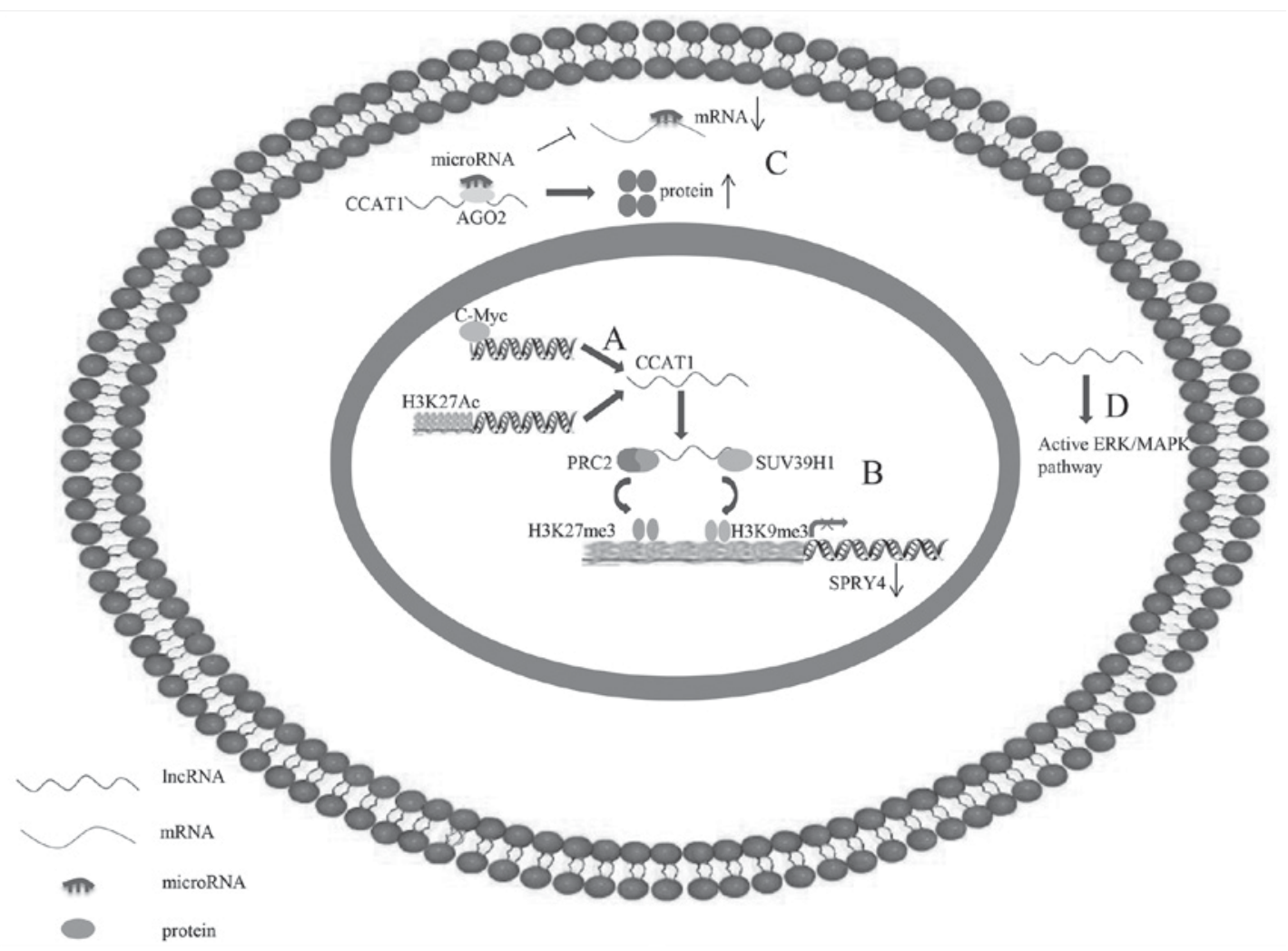

Figure 2. Underlying regulatory mechanisms of CCAT1 in human cancer. (A) C-Myc is able to directly bind to E-box element in CCAT1 promoter regions to activate CCAT1 transcription. (B) CCAT1, which may be activated by H3K27-acetylation, is able to serve as a scaffold for PRC2 and SUV39H1, and modulate the histone methylation of promoter of SPRY4, thereby epigenetically silencing tumour suppressor gene SPRY4. (C) CCAT1 additionally functions as competing endogenous RNA by sponging microRNA to free its target mRNA for protein production. (D) CCAT1 may activate the ERK/MAPK signalling pathway. CCAT1, colon cancer-associated transcript 1; ERK/MAPK, extracellular signal-regulated kinase/mitogen-activated protein kinase; lncRNA, long non-coding RNA; PRC2, polycomb repressive complex 2; SPRY4, sprouty RTK signalling antagonist 4; SUV39H1, suppressor of variegation 3-9 homolog 1.

high mortality rates) worldwide (49,50). Despite the progress achieved in the diagnosis and therapy of LSCC in the past few decades, the survival rate has not noticeably increased (51). Therefore, novel molecular targets for LSCC are urgently required.

CCAT1 expression was higher in LSCC compared with matched normal tissues, and it was associated with advanced clinical stage $(31,52)$. Mechanistically, CCAT1 overexpression promotes LSCC cell proliferation and invasion by suppressing let-7 expression and enhancing its target genes Myc and HMGA2, or by enhancing the zinc finger protein, $\mathrm{X}$-linked, by sponging microRNA-218 (Fig. 3) (31,52).

Esophageal squamous cell carcinoma (ESCC). ESCC is developing at the fastest rate among all cancer types in East Asia $(53,54)$. Therefore, a deeper understanding of the 


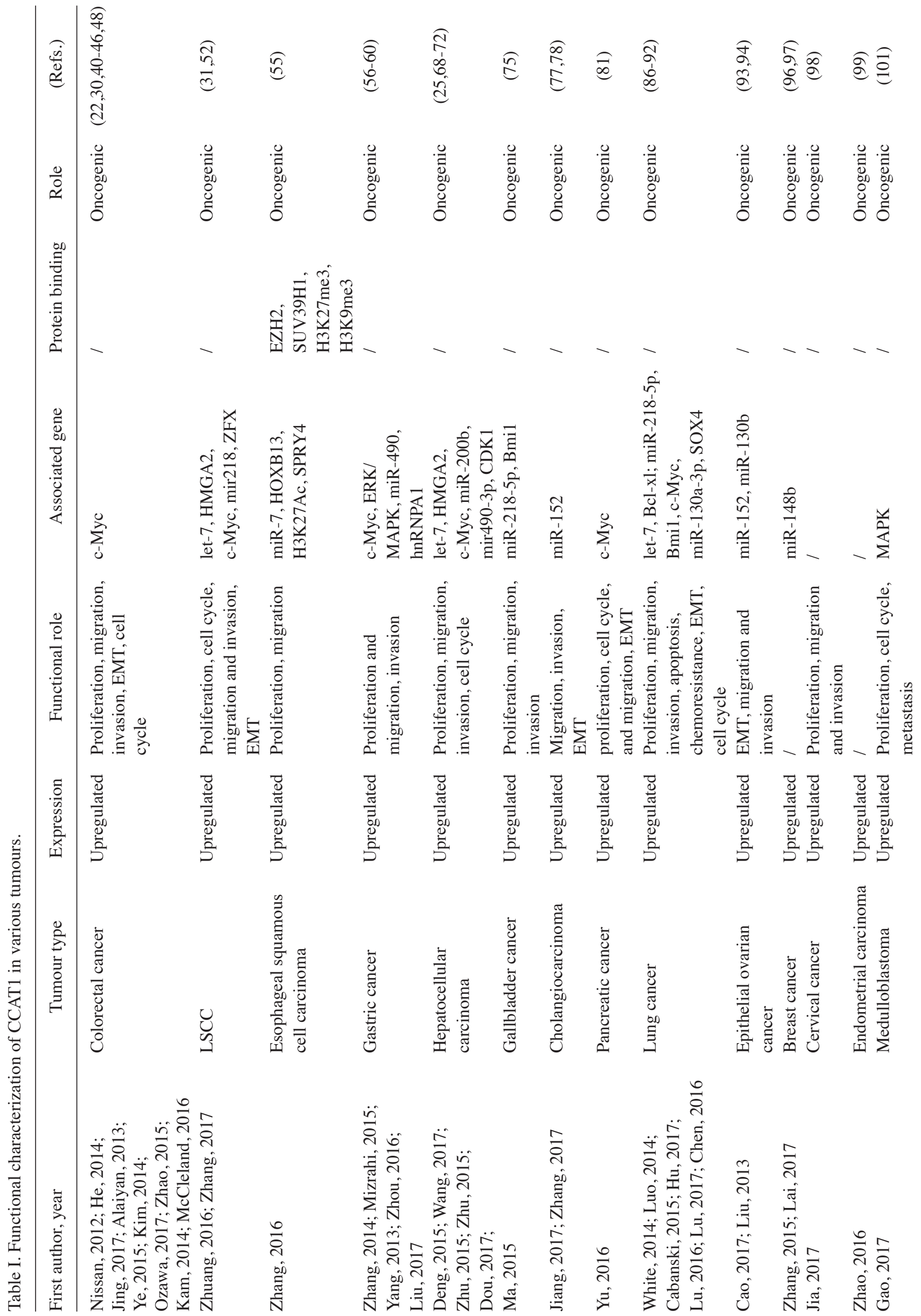




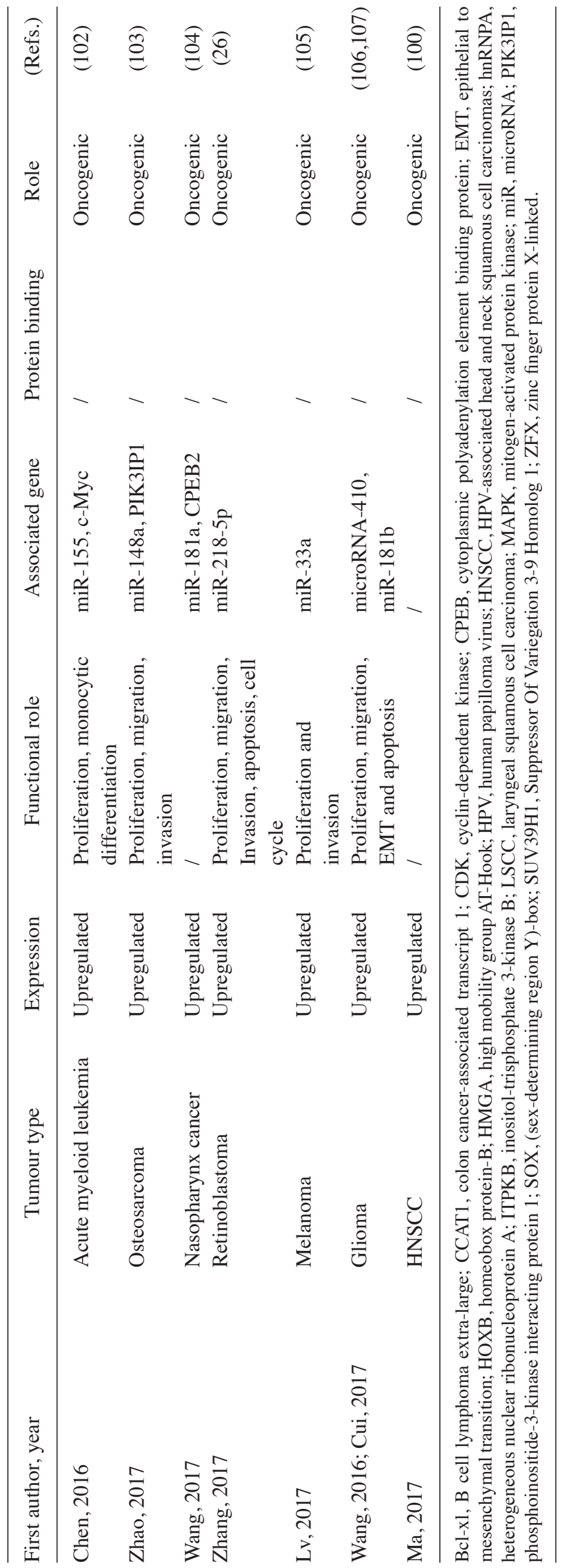



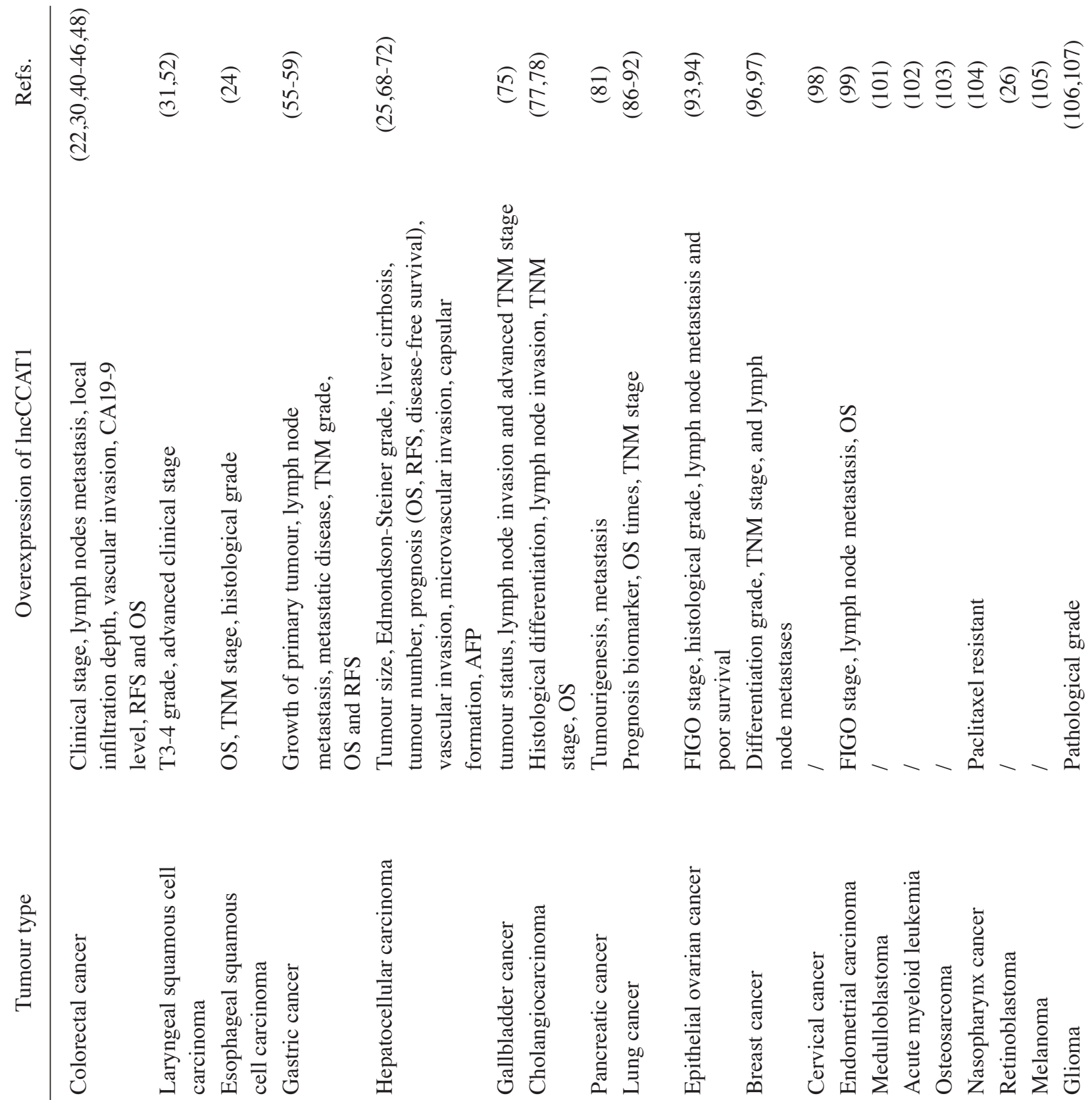

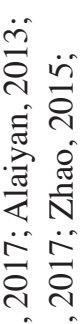

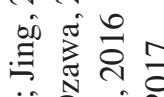

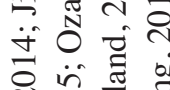

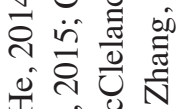

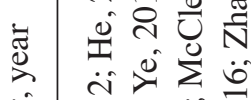

으

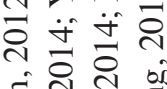

药结芯

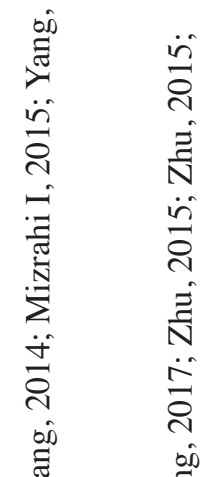

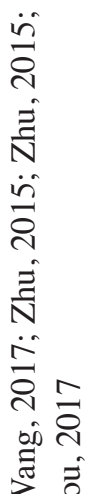

$\stackrel{\check{c}}{\circ}$

密

$\ddot{n}$

竎

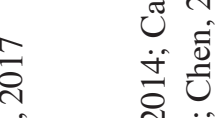

范。

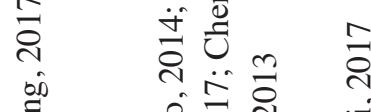

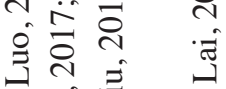

$\dot{\Xi}$

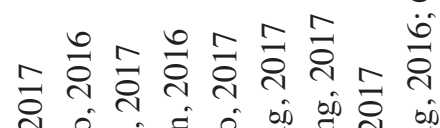

त. को

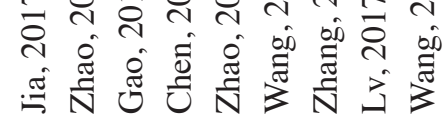


molecular basis underlying ESCC is required to improve diagnosis and treatment.

CCAT1 is frequently increased inESCC, which partly results from H3K27-acetylation activation of promoter (Fig. 2B), and it is an independent prognostic factor for advanced histological grade of patients with ESCC (55). Furthermore, proliferation and migration, in vitro and in vivo, are significantly supressed following knockdown of CCAT1 (55). Zhang et al (55) identified that in the nucleus, CCAT1 has the role of a modular scaffold for polycomb repressive complex 2 and Suppressor Of Variegation 3-9 Homolog 1. This combination modulates the histone methylation of sprouty RTK signalling antagonist 4 (SPRY4) promoter, thereby epigenetically silencing tumour suppressor genes SPRY4 (Fig. 2B). In the cytoplasm, CCAT1 upregulates HOXB13 as a molecular decoy for miR-7, thereby facilitating cell viability and migration (Fig. 3).

$G C$. GC is one of the most lethal malignancies worldwide (1). The expression of CCAT1 is notably upregulated in GC compared with normal tissue $(56,57)$. Notably, the CCAT1 expression levels in adjacent normal tissues from GC cases were higher compared with a negative control group, and recurrent $\mathrm{GC}$ tissues demonstrated the highest expression levels among these groups (57). Furthermore, CCAT1 overexpression is positively associated with metastasis, TNM grade, OS and RFS in patients with GC (58-60).

In vitro, abnormal CCAT1 expression levels promote GC cell proliferation, migration and invasion $(58,59)$. Similar to CRC, c-Myc activates the promoter and increases CCAT1 expression levels by directly binding to E-box elements (58). Zhang et al (56) demonstrated that CCAT1 was involved in the ERK/MAPK signalling pathway to promote the growth of GC (Fig. 2D). Another previous study suggested that CCAT1 may additionally function as ceRNA by sponging miR-490 and free miR-490 target heterogeneous nuclear RNP A1 (hnRNPA1) for tumourigenesis in GC (Fig. 3) (59); the relevance has been verified in breast, colorectal, lung and glioma cancer (61-65).

HCC. HCC is the third leading cause of tumour-induced mortality worldwide and accounts for a large proportion of mortalities in China $(3,66)$. Despite recent progress in experimental oncology, patients with HCC continue to have poor long-term prognosis (67). Therefore, it is crucial to identify reliable biomarkers of HCC to develop novel clinical strategies and increase the survival rates of patients with HCC.

CCAT1 expression levels are higher in HCC compared with pair-matched healthy hepatic tissues, particularly in highly metastatic HCC $(25,68)$. Upregulation of CCAT1 has been identified to be positively associated with tumour size, liver cirrhosis, tumour number, vascular invasion, microvascular invasion, capsular formation, Edmondson-Steiner grade and $\alpha$ foetal protein, and it is an independent risk factor for disease-free survival and OS (25,68-70). Additionally, CCAT1 overexpression significantly accelerates HCC cell proliferation, migration and invasion, in vitro $(25,68,69)$.

Similar to CRC and LSCC, CCAT1 activated by c-Myc (70), promotes HCC proliferation and metastasis by functioning as a let-7 sponge to supress its endogenous targets, HMGA2 and c-Myc (25). Furthermore, the CCAT1/miR-200b and CCAT1/miR-490-3p/cyclin-dependent kinase 1 

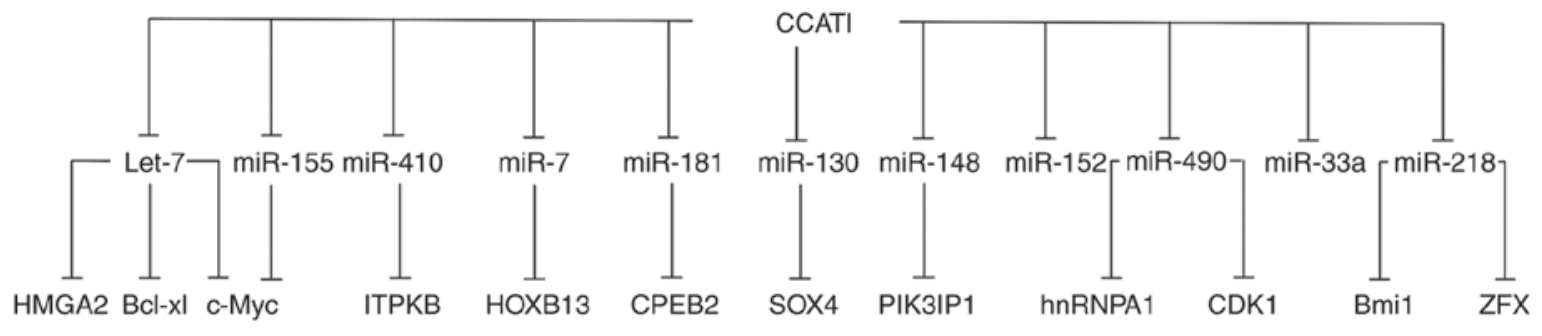

Figure 3. CCAT1 interacts with various target genes by sponging different miRs. Bcl-xl, B cell lymphoma extra-large; CCAT1, colon cancer-associated transcript 1; CDK, cyclin-dependent kinase; CPEB, cytoplasmic polyadenylation element binding protein; HOXB, homeobox protein-B; HMGA, high mobility group AT-Hook; hnRNPA, heterogeneous nuclear ribonucleoprotein A; ITPKB, inositol-trisphosphate 3-kinase B; miR, microRNA; SOX, (sex-determining region Y)-box; ZFX, zinc finger protein X-linked.

regulatory pathway may additionally promote $\mathrm{HCC}$ progression (Fig. 3) (71,72). These findings implicate the potential role of CCAT1 in HCC therapies.

Gallbladder cancer (GBC). Gallbladder cancer (GBC) is the most common cancer of the biliary tract, and has a particularly high incidence in Chile, Japan and northern India (73). Despite the great efforts made to identify novel molecular abnormalities that contribute to GBC, many remain unknown (74).

CCAT1 is upregulated in GBC and is positively correlated with tumour status, lymph node invasion and advanced TNM stage (75). CCAT1 was able to improve the proliferation, migration and invasion of GBC cells in vitro (75). These effects are dependent on its competitive binding to miR-218-5p, thereby regulating Bmil (Fig. 3) (75).

Cholangiocarcinoma (CCA). Without typical symptoms and sensitive indicators, the diagnosis of the majority of CCA cases typically occurs at a late stage, with poor prognosis (76). Therefore, identifying more efficient markers and examining the molecular mechanism underlying the carcinogenesis and progression of CCA is urgently required.

It was observed that CCAT1 expression levels are elevated in CCA compared with the adjacent normal controls, and it is positively associated with histological differentiation, lymph node invasion, TNM stage and OS in patients with CCA (77). A previous mechanistic study identified that CCAT1 led to migration, invasion and EMT activation by binding to miR-152 in CCA cells (78).

Pancreatic cancer $(P C)$. PC is a lethal digestive system malignancy (1) due to the late detection of the disease and the lack of effective therapies for terminally staged tumours (79); only $25 \%$ of patients with metastatic PC have a five-year survival rate (80). Therefore, a comprehensive understanding of the molecular mechanisms underlying PC tumourigenesis is urgently required to identify novel therapeutic targets.

CCAT1 expression levels are notably higher in PC specimens and PC cell lines compared with matched noncancerous controls (81). In addition, the silencing of CCAT1 inhibited proliferation and migration, extending the cell cycle progression and decreasing cyclin D1 expression in PC cells (82). In CRC, GC and HCC, c-Myc was able to activate CCAT1 expression by targeting its promoter at the E-box, thereby contributing to tumourigenesis and metastasis in PC, suggesting that CCAT1 may serve as a potential therapeutic target for PC.
$L C$. LC is one of the frequent causes of cancer mortality worldwide, resulting in more than one million mortalities annually $(83,84)$. Despite advancements in clinical and experimental oncology, effective diagnostic and prognostic biomarkers and alternative treatment options are still required due to the late diagnosis and quick onset of chemoresistance (85).

Overexpression of CCAT1 is evident in non-small cell lung cancer (NSCLC) and is associated with reduced OS times, advanced disease stage and lymph node involvement (86-88). Knockdown of CCAT1 suppressed the proliferation, migration and invasion, and reversed the EMT of NSCLC cells (88). Furthermore, CCAT1 was able to enhance cisplatin resistance of NSCLC cells through the CCAT1/miR-130a-3p/ sex-determining region Y-box (SOX)4 axis (Fig. 3) (89).

As cigarette smoking is a key risk factor for LC, Lu et al (90) determined that CCAT1 was able to regulate neoplastic activity by epigenetically silencing miR-218 and acting through Bmil, thereby promoting cell cycle progression in the cigarette smoke extract (CSE)-induced carcinogenesis of human bronchial epithelial (HBE) cells (Fig. 3). In a subsequent study, the authors additionally demonstrated that CCAT1 bound let-7c and subsequently upregulated c-Myc, which was able to promote CSE-transformed HBE cell proliferation and invasion (Fig. 3) (91).

CCAT1 is upregulated in the docetaxel-resistant lung adenocarcinoma (LAD) cell line, and suppression of CCAT1 inhibits cell proliferation, enhances apoptosis, decreases chemoresistance, and reverses the docetaxel-resistant LAD cells-induced EMT phenotype (92). Furthermore, CCAT1 exerted the oncogenic function in LAD cells, partially by competitive sponging (let-7c) to prevent the inhibition of $\mathrm{B}$ cell lymphoma-extra-large, thereby resulting in chemoresistance and EMT in docetaxel-resistant LAD cells (Fig. 3).

These results suggested that CCAT1 is a critical oncogene associated with the diagnosis and prognosis of various types of lung cancer, as well as a potential target for strengthening the response to chemotherapeutic drugs in lung cancer.

Epithelial ovarian cancer (EOC). EOC, characterized by quick disease progression, is a lethal gynaecological cancer (66). CCAT1 upregulation in EOC was associated with the International Federation of Gynaecology and Obstetrics stage, histological grade, lymph node metastasis and poor survival (93). In addition, CCAT1 promotes EOC cell migration, invasion and EMT by sponging miR-152 and miR-130b, 
which may function as a potential molecular target for EOC (Fig. 3) (93,94).

Breast cancer $(B C)$. BC is a prevalent malignancy among women, and it affects approximately one million women worldwide (95). Among patients with BC, high CCAT1 expression levels are significantly associated with differentiation grade and TNM stage compared with other clinicopathological factors (96). Furthermore, reduced CCAT1 may improve breast cancer radiosensitivity by negatively regulating miR-148b expression (Fig. 3) (97). These previous studies provide a crucial basis to identify more effective treatments for breast cancer.

Other human cancer types. The aberrant upregulation of CCAT1 was detected in human papillomavirus (HPV)-associated head and neck squamous cell carcinomas (HNSCC), cervical cancer, endometrial carcinoma, medulloblastoma, acute myeloid leukaemia (AML), osteosarcoma, nasopharyngeal carcinoma (NPC), retinoblastoma (RB), melanoma and glioma cancer (26,98-107) (Tables I and II), and it was associated with clinicopathological features, in addition to clinical outcomes. Furthermore, CCAT1 may serve as an intermediate in HPV16 infection and promote myeloid-derived suppressor cell aggregation in $\operatorname{HNSCC}(100,108)$.

Mechanistically, CCAT1 may promote medulloblastoma cell proliferation and metastasis through the MAPK signaling pathway (Fig. 2D), as in GC (101). In addition, CCAT1 inhibits monocytic differentiation and promotes AML cell growth by sequestering tumour suppressive miR-155, thereby upregulating c-Myc (Fig. 3) (102). Additionally, the biological function of osteosarcoma cells was regulated by the CCAT1/miR-148a/phosphatidyl inositol 3-kinase interacting protein 1 signaling pathway (Fig. 3) (103). Wang et al (104) observed that upregulated CCAT1 significantly weakened the sensitivity of paclitaxel in NPC cells through the miR-181a/CPEB2 axis (Fig. 3).

CCAT1 promotes RB and melanoma tumourigenesis and metastasis through negative modulation of miR-218-5p and miR-33a, respectively (Fig. 3) (26,105). Furthermore, CCAT1 was able to promote glioma cell progress by inhibiting miR-410 and miR-181b, which provides novel insight into the proliferation of glioma (Fig. 3) (106,107).

\section{Future directions}

Overexpression of the oncogenic lncRNA CCAT1 occurs in numerous cancer types, and positively correlates with clinical progress and cell biological function via complex molecular mechanisms. Notably, to date, the mechanism of ceRNA has been investigated in a number of previous studies. Therefore, further research is required to investigate the downstream molecular mechanism of CCAT1 dysregulation. Furthermore, CCAT1 may be activated by c-Myc and H3K27-acetylation in various tumours, which suggests that the upstream regulatory mechanisms underlying CCAT1 deregulation in various cancer types may be diverse and remain to be elucidated. Pertinent to clinical practice, to improve the clinical utilisation of CCAT1 as a biomarker for the diagnosis and treatment of cancer, larger cohorts of CCAT1 are required in future studies.
Additionally, identifying sensitive and high-throughput quantification methods to identify CCAT1 as a specific and early cancer biomarker, providing clinical benefits in future studies, is required.

\section{Acknowledgements}

Not applicable.

\section{Funding}

The present study was supported by the Project of Standard Diagnosis and Treatment of Key Disease of Jiangsu Province (grant no. BE2015722), Project of the peak of the six talents of Jiangsu Province (grant no. WSN-018) and Scientific Research Foundation for Health of Jiangsu Province (grant no. H201408).

\section{Availability of data and materials}

The analyzed data sets generated during the study are available from the corresponding author on reasonable request.

\section{Authors' contributions}

NW, YY, QL and LM conceived and designed the study. NW, $\mathrm{YY}, \mathrm{BX}$ and $\mathrm{MZ}$ researched the literature and performed data analysis. NW drafted the manuscript. QL and LM revised the article. All authors read and approved the final manuscript.

\section{Ethics approval and consent to participate}

Not applicable.

\section{Patient consent for publication}

Not applicable.

\section{Competing interests}

The authors declare they have no competing interests.

\section{References}

1. Siegel RL, Miller KD and Jemal A: Cancer Statistics, 2017. CA Cancer J Clin 67: 7-30, 2017.

2. Siegel RL, Miller KD and Jemal A: Cancer statistics, 2016. CA Cancer J Clin 66: 7-30, 2016.

3. Torre LA, Bray F, Siegel RL, Ferlay J, Lortet-Tieulent J and Jemal A: Global cancer statistics, 2012. CA Cancer J Clin 65: 87-108, 2015.

4. Mattick JS and Makunin IV: Non-coding RNA. Hum Mol Genet 15 Spec No 1: R17-R29, 2006.

5. Bonasio R and Shiekhattar R: Regulation of transcription by long noncoding RNAs. Annu Rev Genet 48: 433-455, 2014.

6. Eddy SR: Non-coding RNA genes and the modern RNA world. Nat Rev Genet 2: 919-929, 2001.

7. Guttman M and Rinn JL: Modular regulatory principles of large non-coding RNAs. Nature 482: 339-346, 2012.

8. Batista PJ and Chang HY: Long noncoding RNAs: Cellular address codes in development and disease. Cell 152: 1298-1307, 2013.

9. St Laurent G, Wahlestedt C and Kapranov P: The Landscape of long noncoding RNA classification. Trends Genet 31: 239-251, 2015 . 
10. Gupta RA, Shah N, Wang KC, Kim J, Horlings HM, Wong DJ, Tsai MC, Hung T, Argani P, Rinn JL, et al: Long non-coding RNA HOTAIR reprograms chromatin state to promote cancer metastasis. Nature 464: 1071-1076, 2010.

11. Yildirim E, Kirby JE, Brown DE, Mercier FE, Sadreyev RI, Scadden DT and Lee JT: Xist RNA is a potent suppressor of hematologic cancer in mice. Cell 152: 727-742, 2013.

12. Hung T, Wang Y, Lin MF, Koegel AK, Kotake Y, Grant GD, Horlings HM, Shah N, Umbricht C, Wang P, et al: Extensive and coordinated transcription of noncoding RNAs within cell-cycle promoters. Nat Genet 43: 621-629, 2011.

13. Guttman M, Donaghey J, Carey BW, Garber M, Grenier JK, Munson G, Young G, Lucas AB, Ach R, Bruhn L, et al: lincRNAs act in the circuitry controlling pluripotency and differentiation. Nature 477: 295-300, 2011.

14. Gomez JA, Wapinski OL, Yang YW, Bureau JF, Gopinath S, Monack DM, Chang HY, Brahic M and Kirkegaard K: The NeST long ncRNA controls microbial susceptibility and epigenetic activation of the interferon- $\gamma$ locus. Cell 152: 743-754, 2013.

15. Huarte M, Guttman M, Feldser D, Garber M, Koziol MJ, Kenzelmann-Broz D, Khalil AM,Zuk O, Amit I, Rabani M, et al: A large intergenic noncoding RNA induced by p53 mediates global gene repression in the p53 response. Cell 142: 409-419, 2010 .

16. Wilusz JE, Sunwoo H and Spector DL: Long noncoding RNAs: Functional surprises from the RNA world. Genes Dev 23: 1494-1504, 2009.

17. Engreitz JM, Pandya-Jones A, McDonel P, Shishkin A, Sirokman K, Surka C, Kadri S, Xing J, Goren A, Lander ES, et al: The Xist lncRNA exploits three-dimensional genome architecture to spread across the X chromosome. Science 341: 1237973, 2013.

18. Li W, Notani D, Ma Q, Tanasa B, Nunez E, Chen AY, Merkurjev D, Zhang J, Ohgi K, Song X, et al: Functional roles of enhancer RNAs for oestrogen-dependent transcriptional activation. Nature 498: 516-520, 2013.

19. Ørom UA, Derrien T, Beringer M, Gumireddy K, Gardini A, Bussotti G, Lai F, Zytnicki M, Notredame C, Huang Q, et al: Long noncoding RNAs with enhancer-like function in human cells. Cell 143: 46-58, 2010

20. Di Ruscio A, Ebralidze AK, Benoukraf T, Amabile G, Goff LA, Terragni J, Figueroa ME, De Figueiredo Pontes LL, Alberich-Jorda M, Zhang P, et al: DNMT1-interacting RNAs block gene-specific DNA methylation. Nature 503: 371-376, 2013.

21. Hansen TB, Jensen TI, Clausen BH, Bramsen JB, Finsen B, Damgaard CK and Kjems J: Natural RNA circles function as efficient microRNA sponges. Nature 495: 384-388, 2013.

22. Nissan A, Stojadinovic A, Mitrani-Rosenbaum S, Halle D, Grinbaum R, Roistacher M, Bochem A, Dayanc BE, Ritter G, Gomceli I, et al: Colon cancer associated transcript-1: A novel RNA expressed in malignant and pre-malignant human tissues. Int J Cancer 130: 1598-1606, 2012.

23. Xiang JF, Yin QF, Chen T, Zhang Y, Zhang XO, Wu Z, Zhang S, Wang HB, Ge J, Lu X, et al: Human colorectal cancer-specific CCAT1-L lncRNA regulates long-range chromatin interactions at the MYC locus. Cell Res 24: 513-531, 2014.

24. Wu Y, Tan C, Weng WW, Deng Y, Zhang QY, Yang XQ, Gan HL, Wang T, Zhang PP, Xu MD, et al: Long non-coding RNA Linc00152 is a positive prognostic factor for and demonstrates malignant biological behavior in clear cell renal cell carcinoma. Am J Cancer Res 6: 285-299, 2016.

25. Deng L, Yang SB, Xu FF and Zhang JH: Long noncoding RNA CCAT1 promotes hepatocellular carcinoma progression by functioning as let-7 sponge. J Exp Clin Cancer Res 34: 18, 2015.

26. Zhang H, Zhong J, Bian Z, Fang X, Peng Y and Hu Y: Long non-coding RNA CCAT1 promotes human retinoblastoma SO-RB50 and Y79 cells through negative regulation of miR-218-5p. Biomed Pharmacother 87: 683-691, 2017.

27. Zanke BW, Greenwood CM, Rangrej J, Kustra R, Tenesa A, Farrington SM, Prendergast J, Olschwang S, Chiang T, Crowdy E, et al: Genome-wide association scan identifies a colorectal cancer susceptibility locus on chromosome 8q24. Nat Genet 39: 989-994, 2007 .

28. Yeager M, Orr N, Hayes RB, Jacobs KB, Kraft P, Wacholder S, Minichiello MJ, Fearnhead P, Yu K, Chatterjee N, et al: Genome-wide association study of prostate cancer identifies a second risk locus at 8q24. Nat Genet 39: 645-649, 2007.

29. Younger ST and Rinn JL: 'Lnc'-ing enhancers to MYC regulation. Cell Res 24: 643-644, 2014.
30. He X, Tan X, Wang X, Jin H, Liu L, Ma L, Yu H and Fan Z: C-Myc-activated long noncoding RNA CCAT1 promotes colon cancer cell proliferation and invasion. Tumour Biol 35: 12181-12188, 2014.

31. Zhuang K, Wu Q, Jiang S, Yuan H, Huang S and Li H: CCAT1 promotes laryngeal squamous cell carcinoma cell proliferation and invasion. Am J Transl Res 8: 4338-4345, 2016.

32. Siegel RL, Miller KD, Fedewa SA, Ahnen DJ, Meester RG, Barzi A and Jemal A: Colorectal cancer statistics, 2017. CA Cancer J Clin 67: 177-193, 2017.

33. Kogo R, Shimamura T, Mimori K, Kawahara K, Imoto S, Sudo T, Tanaka F, Shibata K, Suzuki A, Komune S, et al: Long noncoding RNA HOTAIR regulates polycomb-dependent chromatin modification and is associated with poor prognosis in colorectal cancers. Cancer Res 71: 6320-6326, 2011.

34. Ling H, Spizzo R, Atlasi Y, Nicoloso M, Shimizu M, Redis RS Nishida N, Gafà R, Song J, Guo Z, et al: CCAT2, a novel noncoding RNA mapping to 8q24, underlies metastatic progression and chromosomal instability in colon cancer. Genome Res 23: 1446-1461, 2013.

35. Zheng HT, Shi DB, Wang YW, Li XX, Xu Y, Tripathi P, Gu WL, Cai GX and Cai SJ: High expression of lncRNA MALAT1 suggests a biomarker of poor prognosis in colorectal cancer. Int J Clin Exp Pathol 7: 3174-3181, 2014.

36. Wang X, Yang Z, Tian H, Li Y, Li M, Zhao W, Zhang C, Wang T, Liu J, Zhang A, et al: Circulating MIC-1/GDF15 is a complementary screening biomarker with CEA and correlates with liver metastasis and poor survival in colorectal cancer. Oncotarget 8: 24892-24901, 2017.

37. Yue B, Cai D, Liu C, Fang C and Yan D: linc00152 functions as a competing endogenous RNA to confer oxaliplatin resistance and holds prognostic values in colon cancer. Mol Ther 24: 2064-2077, 2016.

38. Luo J, Qu J, Wu DK, Lu ZL, Sun YS and Qu Q: Long non-coding RNAs: A rising biotarget in colorectal cancer. Oncotarget 8: 22187-22202, 2017.

39. Fang L, Lu W, Choi HH, Yeung SC, Tung JY, Hsiao CD, Fuentes-Mattei E, Menter D, Chen C, Wang L, et al: ERK2-dependent phosphorylation of CSN6 is critical in colorectal cancer development. Cancer Cell 28: 183-197, 2015.

40. Jing F, Jin H, Mao Y, Li Y, Ding Y, Fan C and Chen K Genome-wide analysis of long non-coding RNA expression and function in colorectal cancer. Tumour Biol 39 1010428317703650, 2017.

41. Alaiyan B, Ilyayev N, Stojadinovic A, Izadjoo M, Roistacher M, Pavlov V, Tzivin V, Halle D, Pan H, Trink B, et al: Differential expression of colon cancer associated transcript1 (CCAT1) along the colonic adenoma-carcinoma sequence. BMC Cancer 13: 196, 2013.

42. Kim T, Cui R, Jeon YJ, Lee JH, Lee JH, Sim H, Park JK, Fadda P, Tili E, Nakanishi H, et al: Long-range interaction and correlation between MYC enhancer and oncogenic long noncoding RNA CARLo-5. Proc Natl Acad Sci USA 111: 4173-4178, 2014

43. Ye Z, Zhou M, Tian B, Wu B and Li J: Expression of IncRNA-CCAT1, E-cadherin and N-cadherin in colorectal cancer and its clinical significance. Int J Clin Exp Med 8: 3707-3715, 2015.

44. Ozawa T, Matsuyama T, Toiyama Y, Takahashi N, Ishikawa T, Uetake H, Yamada Y, Kusunoki M, Calin G and Goel A: CCAT1 and CCAT2 long noncoding RNAs, located within the 8q.24.21 'gene desert', serve as important prognostic biomarkers in colorectal cancer. Ann Oncol 28: 1882-1888, 2017.

45. Zhao W, Song M, Zhang J, Kuerban M and Wang H: Combined identification of long non-coding RNA CCAT1 and HOTAIR in serum as an effective screening for colorectal carcinoma. Int J Clin Exp Pathol 8: 14131-14140, 2015.

46. Kam Y, Rubinstein A, Naik S, Djavsarov I, Halle D, Ariel I, Gure AO, Stojadinovic A, Pan H, Tsivin V, et al: Detection of a long non-coding RNA (CCAT1) in living cells and human adenocarcinoma of colon tissues using FIT-PNA molecular beacons. Cancer Lett 352: 90-96, 2014.

47. Shi J and Vakoc CR: The mechanisms behind the therapeutic activity of BET bromodomain inhibition. Mol Cell 54: 728-736, 2014

48. McCleland ML, Mesh K, Lorenzana E, Chopra VS, Segal E, Watanabe C, Haley B, Mayba O, Yaylaoglu M, Gnad F and Firestein R: CCAT1 is an enhancer-templated RNA that predicts BET sensitivity in colorectal cancer. J Clin Invest 126: 639-652, 2016. 
49. Ren J, Zhu D, Liu M, Sun Y and Tian L: Downregulation of miR-21 modulates Ras expression to promote apoptosis and suppress invasion of Laryngeal squamous cell carcinoma. Eur J Cancer 46: 3409-3416, 2010.

50. Chu EA and Kim YJ: Laryngeal cancer: Diagnosis and preoperative work-up. Otolaryngol Clin North Am 41: 673-695, 2008.

51. Wang W, Lin P, Han C, Cai W, Zhao X and Sun B: Vasculogenic mimicry contributes to lymph node metastasis of laryngeal squamous cell carcinoma. J Exp Clin Cancer Res 29: 60, 2010.

52. Zhang Y and Hu H:Long non-coding RNA CCAT1/miR-218/ZFX axis modulates the progression of laryngeal squamous cell cancer. Tumour Biol 39: 1010428317699417, 2017.

53. Matsushima $\mathrm{K}$, Isomoto $\mathrm{H}$, Yamaguchi $\mathrm{N}$, Inoue $\mathrm{N}$, Machida H, Nakayama T, Hayashi T, Kunizaki M, Hidaka S, Nagayasu T, et al: MiRNA-205 modulates cellular invasion and migration via regulating zinc finger E-box binding homeobox 2 expression in esophageal squamous cell carcinoma cells J Transl Med 9: 30, 2011.

54. Enzinger PC and Mayer RJ: Esophageal cancer. N Engl J Med 349: 2241-2252, 2003.

55. Zhang E, Han L, Yin D, He X, Hong L, Si X, Qiu M, Xu T, De W, Xu L, et al: H3K27 acetylation activated-long non-coding RNA CCAT1 affects cell proliferation and migration by regulating SPRY4 and HOXB13 expression in esophageal squamous cell carcinoma. Nucleic Acids Res 45: 3086-3101, 2017.

56. Zhang Y, Ma M, Liu W, Ding W and Yu H: Enhanced expression of long noncoding RNA CARLo-5 is associated with the development of gastric cancer. Int J Clin Exp Pathol 7 : 8471-8479, 2014.

57. Mizrahi I, Mazeh H, Grinbaum R, Beglaibter N, Wilschanski M, Pavlov V, Adileh M, Stojadinovic A, Avital I, Gure AO, et al: Colon cancer associated transcript-1 (CCAT1) expression in adenocarcinoma of the stomach. J Cancer 6: 105-110, 2015.

58. Yang F, Xue X, Bi J, Zheng L, Zhi K, Gu Y and Fang G: Long noncoding RNA CCAT1, which could be activated by c-Myc, promotes the progression of gastric carcinoma. J Cancer Res Clin Oncol 139: 437-445, 2013.

59. Zhou B, Wang Y, Jiang J, Jiang H, Song J, Han T, Shi J and Qiao H: The long noncoding RNA colon cancer-associated transcript-1/miR-490 axis regulates gastric cancer cell migration by targeting hnRNPA1. IUBMB Life 68: 201-210, 2016.

60. Liu JN and Shangguan YM: Long non-coding RNA CARLo-5 upregulation associates with poor prognosis in patients suffering gastric cancer. Eur Rev Med Pharmacol Sci 21: 530-534, 2017.

61. Pino I, Pio R, Toledo G, Zabalegui N, Vicent S, Rey N, Lozano MD, Torre W, Garcia-Foncillas J and Montuenga LM: Altered patterns of expression of members of the heterogeneous nuclear ribonucleoprotein (hnRNP) family in lung cancer. Lung Cancer 41: 131-143,. 2003

62. Buvoli M, Cobianchi F, Biamonti G and Riva S: Recombinant hnRNP protein A1 and its N-terminal domain show preferential affinity for oligodeoxynucleotides homologous to intron/exon acceptor sites. Nucleic Acids Res 18: 6595-6600, 1990.

63. Carpenter B, MacKay C, Alnabulsi A, MacKay M, Telfer C, Melvin WT and Murray GI: The roles of heterogeneous nuclear ribonucleoproteins in tumour development and progression. Biochim Biophys Acta 1765: 85-100, 2006.

64. Boukakis G, Patrinou-Georgoula M, Lekarakou M, Valavanis C and Guialis A: Deregulated expression of hnRNP A/B proteins in human non-small cell lung cancer: Parallel assessment of protein and mRNA levels in paired tumour/non-tumour tissues. BMC Cancer 10: 434, 2010.

65. David CJ, Chen M, Assanah M, Canoll P and Manley JL: HnRNP proteins controlled by c-Myc deregulate pyruvate kinase mRNA splicing in cancer. Nature 463: 364-368, 2010.

66. Jemal A, Bray F, Center MM, Ferlay J, Ward E and Forman D: Global cancer statistics. CA Cancer J Clin 61: 69-90, 2011

67. Yang JD and Roberts LR: Hepatocellular carcinoma: A global view. Nat Rev Gastroenterol Hepatol 7: 448-458, 2010.

68. Wang F, Xie C, Zhao W, Deng Z, Yang H and Fang Q: Long non-coding RNA CARLo-5 expression is associated with disease progression and predicts outcome in hepatocellular carcinoma patients. Clin Exp Med 17: 33-43, 2017.

69. Zhu H, Zhou X, Chang H, Li H, Liu F, Ma C and Lu J: CCAT1 promotes hepatocellular carcinoma cell proliferation and invasion. Int J Clin Exp Pathol 8: 5427-5434, 2015.

70. Zhu HQ, Zhou X, Chang H, Li HG, Liu FF, Ma CQ and Lu J: Aberrant expression of CCAT1 regulated by c-Myc predicts the prognosis of hepatocellular carcinoma. Asian Pac J Cancer Prev 16: 5181-5185, 2015.
71. Dou C, Sun L, Jin X, Han M, Zhang B, Jiang X, Lv J and Li T: Long non-coding RNA CARLo-5 promotes tumor progression in hepatocellular carcinoma via suppressing miR-200b expression. Oncotarget 8: 70172-70182, 2017.

72. Dou C, Sun L, Jin X, Han M, Zhang B and Li T: Long non-coding RNA colon cancer-associated transcript 1 functions as a competing endogenous RNA to regulate cyclin-dependent kinase 1 expression by sponging miR-490-3p in hepatocellular carcinoma progression. Tumour Biol 39: 1010428317697572, 2017.

73. Zhu AX, Hong TS, Hezel AF and Kooby DA: Current management of gallbladder carcinoma. Oncologist 15: 168-181, 2010.

74. Jiao Y, Pawlik TM, Anders RA, Selaru FM, Streppel MM Lucas DJ, Niknafs N, Guthrie VB, Maitra A, Argani P, et al: Exome sequencing identifies frequent inactivating mutations in BAP1, ARID1 A and PBRM1 in intrahepatic cholangiocarcinomas. Nat Genet 45: 1470-1473, 2013.

75. Ma MZ, Chu BF, Zhang Y, Weng MZ, Qin YY, Gong W and Quan ZW: Long non-coding RNA CCAT1 promotes gallbladder cancer development via negative modulation of miRNA-218-5p. Cell Death Dis 6: e1583,2015.

76. Khan SA, Thomas HC, Davidson BR and Taylor-Robinson SD: Cholangiocarcinoma. Lancet 366: 1303-1314, 2005.

77. Jiang XM, Li ZL, Li JL, Zheng WY, Li XH, Cui YF and Sun DJ: LncRNA CCAT1 as the unfavorable prognostic biomarker for cholangiocarcinoma. Eur Rev Med Pharmacol Sci 21: 1242-1247, 2017.

78. Zhang S, Xiao J, Chai Y, Du YY, Liu Z, Huang K, Zhou X and Zhou W: LncRNA-CCAT1 promotes migration, invasion, and EMT in intrahepatic cholangiocarcinoma through suppressing miR-152. Dig Dis Sci 62: 3050-3058, 2017.

79. Li C, Heidt DG, Dalerba P, Burant CF, Zhang L, Adsay V, Wicha M, Clarke MF and Simeone DM: Identification of pancreatic cancer stem cells. Cancer Res 67: 1030-1037, 2007.

80. Von Hoff DD, Ervin T, Arena FP, Chiorean EG, Infante J, Moore M, Seay T, Tjulandin SA, Ma WW, Saleh MN, et al: Increased survival in pancreatic cancer with nab-paclitaxel plus gemcitabine. N Engl J Med 369: 1691-1703, 2013.

81. Yu Q, Zhou X, Xia Q, Shen J, Yan J, Zhu J, Li X and Shu M: Long non-coding RNA CCAT1 that can be activated by c-Myc promotes pancreatic cancer cell proliferation and migration. Am J Transl Res 8: 5444-5454, 2016.

82. Bartek $\mathbf{J}$ and Lukas J: DNA repair: Cyclin D1 multitasks. Nature 474: 171-172, 2011.

83. Bray F, Jemal A, Grey N, Ferlay J and Forman D: Global cancer transitions according to the Human Development Index (2008-2030): A population-based study. Lancet Oncol 13: 790-801, 2012.

84. Ferlay J, Soerjomataram I, Dikshit R, Eser S, Mathers C, Rebelo M, Parkin DM, Forman D and Bray F: Cancer incidence and mortality worldwide: Sources, methods and major patterns in GLOBOCAN 2012. Int J Cancer 136: E359-E386, 2015.

85. Roth A and Diederichs S: Long noncoding RNAs in lung cancer. Curr Top Microbiol Immunol 394: 57-110, 2016.

86. White NM, Cabanski CR, Silva-Fisher JM, Dang HX, Govindan R and Maher CA: Transcriptome sequencing reveals altered long intergenic non-coding RNAs in lung cancer. Genome Biol 15: 429, 2014.

87. Luo J, Tang L, Zhang J, Ni J, Zhang HP, Zhang L, Xu JF and Zheng D: Long non-coding RNA CARLo-5 is a negative prognostic factor and exhibits tumor pro-oncogenic activity in non-small cell lung cancer. Tumour Biol 35: 11541-11549, 2014.

88. Cabanski CR, White NM, Dang HX, Silva-Fisher JM, Rauck CE, Cicka D and Maher CA: Pan-cancer transcriptome analysis reveals long noncoding RNAs with conserved function. RNA Biol 12: 628-642, 2015.

89. Hu B, Zhang H, Wang Z, Zhang F, Wei H and Li L: LncRNA CCAT1/miR-130a-3p axis increases cisplatin resistance in non-small-cell lung cancer cell line by targeting SOX4. Cancer Biol Ther 18: 974-983, 2017.

90. Lu L, Xu H, Luo F, Liu X, Lu X, Yang Q, Xue J, Chen C, Shi L and Liu Q: Epigenetic silencing of miR-218 by the lncRNA CCAT1, acting via BMI1, promotes an altered cell cycle transition in the malignant transformation of HBE cells induced by cigarette smoke extract. Toxicol Appl Pharmacol 304: 30-41, 2016.

91. Lu L, Qi H, Luo F, Xu H, Ling M, Qin Y, Yang P, Liu X, Yang Q, Xue J, et al: Feedback circuitry via let-7c between lncRNA CCAT1 and c-Myc is involved in cigarette smoke extract-induced malignant transformation of HBE cells. Oncotarget 8: 19285-19297, 2017. 
92. Chen J, Zhang K, Song H, Wang R, Chu X and Chen L: Long noncoding RNA CCAT1 acts as an oncogene and promotes chemoresistance in docetaxel-resistant lung adenocarcinoma cells. Oncotarget 7: 62474-62489, 2016.

93. Cao Y, Shi H, Ren F, Jia Y and Zhang R: Long non-coding RNA CCAT1 promotes metastasis and poor prognosis in epithelial ovarian cancer. Exp Cell Res 359: 185-194, 2017.

94. Liu SP, Yang JX, Cao DY and Shen K: Identification of differentially expressed long non-coding RNAs in human ovarian cancer cells with different metastatic potentials. Cancer Biol Med 10: 138-141, 2013.

95. DeSantis C, Ma J, Bryan L and Jemal A: Breast cancer statistics, 2013. CA Cancer J Clin 64: 52-62, 2014

96. Zhang XF, Liu T, Li Y and Li S: Overexpression of long non-coding RNA CCAT1 is a novel biomarker of poor prognosis in patients with breast cancer. Int J Clin Exp Pathol 8: 9440-9445, 2015

97. Lai Y, Chen Y, Lin Y and Ye L: Down-regulation of LncRNA CCAT1 enhances radiosensitivity via regulating miR-148b in breast cancer. Cell Biol Int 42: 227-236, 2018

98. Jia L, Zhang Y, Tian F, Chu Z and Xin H: Long noncoding RNA colon cancer associated transcript-1 promotes the proliferation, migration and invasion of cervical cancer. Mol Med Rep 16 5587-5591, 2017.

99. Zhao X, Wei X, Zhao L, Shi L, Cheng J, Kang S, Zhang H, Zhang J, Li L, Zhang H and Zhao W: The rs6983267 SNP and long non-coding RNA CARLo-5 are associated with endometrial carcinoma. Environ Mol Mutagen 57: 508-515, 2016.

100. Ma X, Sheng S, Wu J, Jiang Y, Gao X, Cen X, Wu J, Wang S, Tang Y, Tang Y and Liang X: LncRNAs as an intermediate in HPV16 promoting myeloid-derived suppressor cell recruitment of head and neck squamous cell carcinoma. Oncotarget 8: 42061-42075, 2017
101. Gao R, Zhang R, Zhang C,Zhao L and Zhang Y: Long noncoding RNA CCAT1 promotes cell proliferation and metastasis in human medulloblastoma via MAPK pathway. Tumori 104: 43-50, 2018

102. Chen L, Wang W, Cao L, Li Z and Wang X: Long non-coding RNA CCAT1 acts as a competing endogenous RNA to regulate cell growth and differentiation in acute myeloid leukemia. Mol Cell 39: 330-336, 2016

103. Zhao J and Cheng L: Long non-coding RNA CCAT1/miR-148a axis promotes osteosarcoma proliferation and migration through regulating PIK3IP1. Acta Biochim Biophys Sin (Shanghai) 49: 503-512, 2017

104. Wang Q, Zhang W and Hao S: LncRNA CCAT1 modulates the sensitivity of paclitaxel in nasopharynx cancers cells via miR-181a/CPEB2 axis. Cell Cycle 16: 795-801, 2017.

105. Lv L, Jia JQ and Chen J: LncRNA CCAT1 Upregulates Proliferation and Invasion in Melanoma Cells Via Suppressing miR-33a. Oncol Res 26: 201-208, 2018

106. Wang ZH, Guo XQ, Zhang QS, Zhang JL, Duan YL, Li GF and Zheng DL: Long non-coding RNA CCAT1 promotes glioma cell proliferation via inhibiting microRNA-410. Biochem Biophys Res Commun 480: 715-720, 2016.

107. Cui B, Li B, Liu Q and Cui Y: IncRNA CCAT1 promotes glioma tumorigenesis by sponging miR-181b. J Cell Biochem 118: 4548-4557, 2017.

108. Gabrilovich DI and Nagaraj S: Myeloid-derived suppressor cells as regulators of the immune system. Nat Rev Immunol 9: 162-174, 2009.

cc) (i) $(\Theta$ This work is licensed under a Creative Commons (c) ${ }_{\mathrm{EY}} \mathrm{NC}$ ND Attribution-NonCommercial-NoDerivatives 4.0 International (CC BY-NC-ND 4.0) License. 